\title{
Discours
}

Revue de linguistique, psycholinguistique et

informatique. A journal of linguistics, psycholinguistics

and computational linguistics

$9 \mid 2011$

Varia

\section{What can children tell us about the fixedness of idiomatic phrases? The psycholinguistic relevance of a linguistic model}

\section{Marianna Mini, Kleopatra Diakogiorgi et Aggeliki Fotopoulou}

\section{OpenEdition \\ Journals}

Édition électronique

URL : http://journals.openedition.org/discours/8579

DOI : $10.4000 /$ discours. 8579

ISSN : 1963-1723

Éditeur :

Laboratoire LATTICE, Presses universitaires de Caen

\section{Référence électronique}

Marianna Mini, Kleopatra Diakogiorgi et Aggeliki Fotopoulou, « What can children tell us about the fixedness of idiomatic phrases? The psycholinguistic relevance of a linguistic model », Discours [En ligne], 9 | 2011, mis en ligne le 20 décembre 2011, consulté le 30 avril 2019. URL : http:// journals.openedition.org/discours/8579; DOI : 10.4000/discours.8579

\section{cc)}

Discours est mis à disposition selon les termes de la licence Creative Commons Attribution - Pas d'Utilisation Commerciale - Pas de Modification 4.0 International. 

Revue de linguistique, psycholinguistique et informatique

\title{
What can children tell us about the fixedness of idiomatic phrases? \\ The psycholinguistic relevance of a linguistic model
}

\author{
Marianna Mini \\ University of Patras, Greece \\ Kleopatra Diakogiorgi \\ University of Patras, Greece \\ Aggeliki Fotopoulou \\ Institute for Language and Speech Processing (ILSP), Athens, Greece
}

Marianna Mini, Kleopatra Diakogiorgi et Aggeliki Fotopoulou, «What can children tell us about the fixedness of idiomatic phrases? The psycholinguistic relevance of a linguistic model», Discours [En ligne], 9 | 2011, mis en ligne le 20 décembre 2011.

URL: http://discours.revues.org/8579. Consulté le 20 décembre 2011. 



\title{
What can children tell us \\ about the fixedness of idiomatic phrases? The psycholinguistic relevance of a linguistic model
}

\author{
Marianna Mini \\ University of Patras, Greece \\ Kleopatra Diakogiorgi \\ University of Patras, Greece \\ Aggeliki Fotopoulou \\ Institute for Language and Speech Processing (ILSP), Athens, Greece
}

The present paper contains two distinct yet intricately linked studies concerning idiomatic phrases in Greek: a linguistic study and a psycholinguistic study. The linguistic study aims at investigating the degree of fixedness of idiomatic phrases, through a semantic-lexical categorization of 470 phrases with fixed subject. Three phrase categories were distinguished: typical phrases characterized by a strong semantic-lexical articulation between their constituents, and non-typical phrases, in which the constituents have a certain semantic autonomy. Non-typical phrases were further categorized into a) quasi-phrases and b) conventionalized phrases, the constituents of which have the highest degree of semantic autonomy. A linguistic model was developed named "graded fixedness model", and the psycholinguistic relevance of the model assessed by examining idiom comprehension in Greek elementary school children, aged 7.5 and 9.5 years old. To achieve this, a psycholinguistic study was then carried out. Children were presented with 8 typical, 8 quasi and 8 conventionalized phrases. For each phrase, they were asked to choose the one they thought correct out of three interpretations proposed (idiomatic, literal and other). The research findings presented and discussed herein provide evidence supporting the psychological reality of the notion of semantic autonomy even for the younger children's processing which was overall quite poor: thus, the greater the semantic autonomy of a phrase's constituents, the easier the access to its idiomatic meaning.

Keywords: graded fixedness model, idiomatic phrase, semantic autonomy, elementary school children, development, psycholinguistic relevance

Le présent article comporte deux études distinctes mais étroitement liées concernant les phrases idomatiques en grec: une étude linguistique et une étude psycholinguistique. L'étude linguistique vise à examiner le degré de figement des phrases idiomatiques, à travers une catégorisation sémantico-lexicale de 470 phrases à sujet fixe. Trois catégories de phrases ont été distinguées: les phrases typiques caractérisées par une articulation sémantico-lexicale forte entre ses constituants et les phrases non typiques dont les constituants ont une certaine autonomie sémantique. Les phrases non typiques ont été catégorisées en a) phrases quasi typiques et b) phrases conventionalisées dont les constituants ont le plus haut degré d'autonomie sémantique. Un modèle linguistique de figement a été développé, appelé «modèle de figement graduel», dont la pertinence psycholinguistique a été testée auprès d'élèves grecs de l'école élémentaire (7,5 et 9,5 ans). Pour ce faire une 
étude psycholinguistique a été menée. Les enfants ont reçu 8 phrases typiques, 8 phrases quasi typiques et 8 phrases conventionalisées. Pour chacune d'elles, il leur a été demandé de choisir, parmi trois interprétations proposées (idiomatique, littérale et autre), celle qu'ils considéraient comme correcte. Les résultats témoignent en faveur de la réalité psychologique de la notion de l'autonomie sémantique, même pour le traitement des enfants les plus jeunes, lequel s'est avéré, généralement, très faible: ainsi, plus l'autonomie sémantique des constituants de la phrase est importante, plus l'accès à sa signification idiomatique est facile.

Mots clés: modèle de figement graduel, phrase idiomatique, autonomie sémantique, enfants de l'école élémentaire, développement, pertinence psycholinguistique

\section{Introduction}

Despite the fact that for more than four decades "fixed" word combinations have been under close scrutiny, the notion of fixedness remains quite fluid in literature. A wide range of different terms and criteria has been used in order to identify various "fixed" word combinations, ranging from collocations to idioms and proverbs. Considerable debate has arisen among syntacticians, semanticists, lexicographers, cognitive linguists and psycholinguists on their syntactic nature (cf. Nunberg, Sag \& Wasow, 1994), the role of literality and figurativeness in their meaning (Gibbs et al., 1997), their lemmatization (Lorentzen, 1996), and on whether they are mentally stored as long words (cf. Swinney \& Cutler, 1979) or not (cf. Gibbs, Nayak \& Cutting, 1989; Glucksberg, 1993).

Traditionally, idioms are multi-word expressions whose idiomatic meaning cannot be deduced from the meaning of their parts (e.g. Bobrow \& Bell, 1973; Chomsky, 1980; Fraser, 1970; Swinney \& Cutler, 1979; M. Gross, 1982, 1988; Van der Linden, 1992). For example, we cannot infer the idiomatic meaning of the idiom bite the dust (i.e., "cease to exist") based on the meanings of the words bite, the, dust.

Nevertheless, in accordance to more recent views, called compositional views (Gibbs \& Nayak, 1989; Gibbs, Nayak \& Cutting, 1989) many idioms are, at least in part, analyzable or decomposable word configurations. Nunberg (1979) was the first to introduce the notion of idioms as combining expressions. Compositionality refers to the fact that the constituents of some idioms "carry identifiable parts of the idiomatic meaning” (Nunberg, Sag \& Wasow, 1994: 496). Based on this notion, in addition to the distinction between semantically decomposable and non-decomposable idioms, Nunberg proposed an idiom classification that emphasized the interaction between an idiom's literal and figurative meanings. According to this classification scheme, idioms vary in their semantic decomposability. He distinguished two types of decomposable idioms: normally decomposable idioms and abnormally decomposable idioms. Normally decomposable idioms' constituents bear a direct relation to the figurative meaning. In pop the question, for example, there is a clear correspondence between pop and question and the relevant parts of the figurative meaning "propose marriage". Abnormally decomposable idioms' constituents bear a metaphorical relation to the figurative meaning. For example, the word maker in meet your maker metaphorically refers to a deity. 
In psycholinguistics, compositionality was introduced by Gibbs and colleagues (Gibbs \& Nayak, 1989; Gibbs, Nayak \& Cutting, 1989). Based on the notion of compositionality proposed by Nunberg, Gibbs and colleagues developed the so-called idiom decomposition hypothesis. This hypothesis asserts that semantically decomposable idioms may be analysed compositionally. Each component is retrieved from the mental lexicon and combined with the other components of the string according to their syntactic relations. In contrast, the meaning of non-decomposable idioms is retrieved directly from the lexicon. Thus, decomposable and non-decomposable idioms are represented differently and processed in different ways. With respect to comprehension, the main prediction of compositional models is that an idiom will be easier to comprehend if its words are related, in any way, to its figurative meaning. For example, the idiom to speak your mind can be analysed to derive its meaning: "to express your feelings or opinions frankly"; in spill the beans - the most commonly cited example of a decomposable idiom in the literature- it is assumed (Gibbs \& Nayak, 1989; Gibbs, Nayak \& Cutting, 1989; Hamblin \& Gibbs, 1999) that there is an isomorphism between the meaning of the individual constituents and the idiomatic meaning of the expression as a whole. Every constituent contributes - literally or metaphorically - to the idiomatic meaning of the expression, with beans corresponding to the secrets and spill to the action of divulging the secrets. Decomposable idioms have been combined with syntactic as well as processing properties: greater flexibility, accuracy, and rapidity of access. Yet, the empirical evidence in support of these claims is not always very consistent (see Tabossi, Fanari \& Wolf, 2008).

\section{The development of idiom comprehension}

As has already been mentioned, past research treated idioms as word configurations in which there is only a slight relationship between literal and figurative meaning. Therefore, knowing the literal meaning of an idiom does not aid the comprehender to find its figurative meaning (Ortony, Turner \& Larson-Shapiro, 1978). This led to the hypothesis that language users (and also children) learn idioms as giant lexical units and not by analysing their constituents (Ackerman, 1982). Nippold and Rudzinski (1993) disagree totally with this hypothesis, claiming on the contrary that idiom comprehension is largely facilitated when language users are capable of analysing them semantically. Transparent idioms provide an excellent opportunity for such an analysis given that the literal meaning of these idioms may help to cue their figurative meaning (Caillies \& Le Sourn-Bissaoui, 2006; Nippold \& Duthie, 2003). Adults and adolescents are sensitive to differences in transparency and can reliably rate the contribution of key words to the meanings of idiomatic expressions (Titone \& Connine, 1999). Further, skilled language comprehenders perform some semantic analysis of the phrase when reading an idiom (Titone \& Connine, 1994, 1999).

When children acquire a similar sensitivity is not clear. Findings about the age at which semantic analysis can be used successfully to process an idiom's meaning 
are conflicting. According to several studies, this is an early developing skill. For example, Gibbs (1987, 199I) found that children as young as 5 years old are better at explaining transparent idioms than opaque ones. Other findings seem to support a late development of this skill. For example, Nippold and Rudzinski (1993) failed to find a positive correlation between transparency and performance on an idiom explanation task for II-year-olds but they found a positive one for I4 and I7-year-olds. Similar findings were obtained by Nippold and Taylor (1995). Nevertheless, younger children seem to be disadvantaged on explanation tasks compared to older ones because of the high degree of metalinguistic effort required by this type of task.

Using a multiple-choice task, Levorato and Cacciari (1999) found that idiom transparency has a facilitatory effect on idiom comprehension for 9-year-olds but not for 7-year-olds. In fact, Levorato and Cacciari (1999) suggest that although semantic analysis can influence idiom comprehension from an early age, the importance and use of this processing skill increases as children get older. A similar pattern of results is reported by Gibbs (199I) between first graders (mean age: 6 years and Io months) and third graders (mean age: 8 years and 9 months). According to Levorato and Cacciari (1999), semantic analysis can be used by children as they acquire a processing skill that develops with age. Thus, it seems that the ability to analyse the internal semantics of an idiom takes some time to develop. In line with Levorato's and Cacciari's findings are those of Cain, Towse and Knight (2009) with a notable exception: even very young children ( $7 / 8$-year-olds) are able to use semantic analysis to derive the meanings of transparent idioms.

\section{The current research}

\subsection{Aims}

The study presented herein contains two intricately linked but distinct studies: a linguistic study and a psycholinguistic study. The linguistic study aims at investigating the extent to which idiomatic phrases are fixed, through a thorough linguistic analysis of 470 phrases with fixed subject in Greek. A linguistic model of fixedness is developed which, being the product of the aforementioned analysis, will be presented immediately afterwards. The aim of the psycholinguistic study, on the other hand, is to precisely assess the empirical adequacy of this model in Greek elementary school students, aged between 7 years and 6 months (henceforth 7.6) and 9 years and 5 months (henceforth 9.5). A series of experiments was conducted, one of which will be presented in this article.

\subsection{Linguistic study: the graded fixedness model}

9 As already mentioned, a linguistic analysis of 470 phrases with fixed subject in Greek was carried out. In order to select the most appropriate phrases the following procedure was followed. First we searched and compared the relative meanings as these appeared in various dictionaries, and then we searched and found examples 
of their use in linguistic contexts. The sources below were used for this purpose: the Dictionary of Modern Greek (Babiniotis, 2002), the Dictionary of Modern Greek (Manolis Triantafyllidis Foundation, 1998), and the Hellenic National Corpus (ILSP, http://hnc.ilps.gr/). Once collected, phrases were classified according to syntactic and semantic criteria and indexed in a lexicon accompanied by their syntactic and semantic properties. These criteria were the same as those used in the past in the framework of "lexicon-grammar" for the classification of French idioms, by M. Gross (1982), and of Greek idioms, by Fotopoulou (1993). These were: I) the semantic criterion, according to which the meaning of an idiom is not derived from the meaning of its parts, and 2) the lexical-structural criterion, according to which one or more elements of the clause are lexically invariable in relation to the verb.

The limits of the present article do not allow a detailed presentation of the syntactic and the semantic properties of the idioms studied. It will suffice to mention that the detailed description of the syntactic properties of phrases with a fixed subject broadly supported the three basic conclusions drawn by M. Gross (1982, 1988) on the basis of his vast empirical work on the classification of 20.000 French idioms:

- idiom fixedness can be limited to only certain constituents of the sentence. For example, the French sentence Max ne porte pas Luc dans son cœur ("Max does not like Luc") demonstrates a combination of fixed and nonfixed elements. The fixedness of this expression relies on the relation of the verb ne pas porter ("not to carry") and the prepositional phrase dans son caur ("in his heart"). The first component Luc is not fixed;

- there are small groups of fixed constructions with similar meanings, allowing some degree of element variation within the idiomatic expression, e.g., in French Max (a ratéla loupé/a manqué) le cocbe ("Max has missed the train") meaning "Max missed his chance" or Max a perdu (la boule/la boussole/le Nord/les pédales, etc.) ("Max has lost [the ball/the compass/the North/the pedals]") meaning "Max flipped out";

- it appears that fixed sentences are located on a continuum, starting from free structured combinations and ending with fixed expressions specified as prototypical, i.e., semantically opaque and structurally fixed ${ }^{1}$. For example: Max a (manqué/loupé/raté) (une chance unique/un beau coup/une bonne occasion/une affaire/le coche) ("Max has missed a unique chance/a good opportunity/a great deal/a great chance/the train") meaning "Max missed his chance".

These conclusions, apart from giving the gist of the syntactic and semantic properties of idioms, also highlight the range and variety of these properties as well as the significant degree of freedom which some of them display. A similar

1. See classification concerning the object classes for synonym structures of this type, as proposed by G. Gross (I994). 
variability was also found by Lamiroy (2003) who, therefore, emphasizes the difficulty in determining the theoretical status of fixed expressions. In other words, fixed and free phrases are not so different.

Nevertheless, concerning the lexical distribution of the phrases, we decided to adopt a much more qualitative rather than a quantitative perspective, going beyond the two basic criteria used by M. Gross.

Certainly, the criterion of restricted distribution is a crucial one for excluding all expressions that contain verbs with a large distribution coming from various semantic fields. However, we assumed that the categorization of the phrases as to the degree of their fixedness would need more subtle criteria than the purely quantitative criterion of restricted distribution. Thus, in each expression we examined the type of relationship between the verb and the subject: is it this particular co-occurrence of this particular verb with this particular noun which produces this particular meaning of the idiom or, conversely, is it possible for this particular verb to be combined with another noun and to still have the same meaning? For example, in the expression

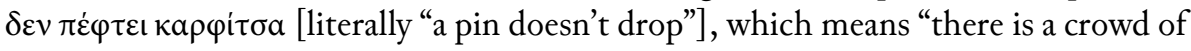
people", the verb cannot be found in another lexical configuration with the same or

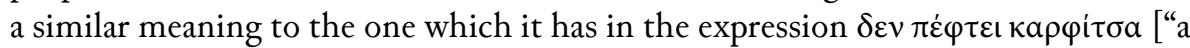
pin doesn't drop"] ${ }^{2}$. In this case, the meaning of the expression derives exclusively from the lexical relationship between its verb and its noun. This is not the case of

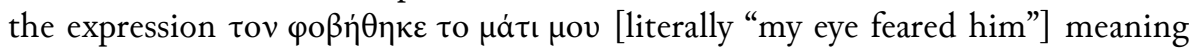
"I was scared stiff by him or his actions" the meaning of which emerges from the lexical meaning of its parts.

Because of this heterogeneity, we preferred, instead of the terms "idiom" or "idiomatic expression", to use the term "phrase" defined as the expression the overall meaning of which does not exclusively emerge from the lexical meanings of its parts. The meaning of the phrase can therefore emerge: a) lexically i.e., from the constituents' lexical meaning, for example $\rho \alpha \gamma i \zeta \varepsilon ı \eta ~ \kappa a \rho \delta ı \dot{\alpha} \mu$ ov [literally "my heart cracks"] meaning "I am in deep grief" or "it broke my heart"; b) conceptually,

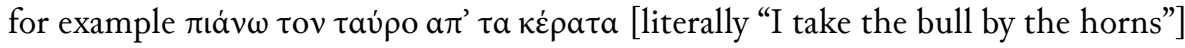
meaning "I face the problem decisively"; c) from the blending of constituents' lexical and conceptual meanings, for example kó $\beta \varepsilon$ to $\mu v \alpha \lambda$ ó tov [literally "his mind cuts"] meaning "he is smart"; and, very rarely, d) neither conceptually nor lexically, for

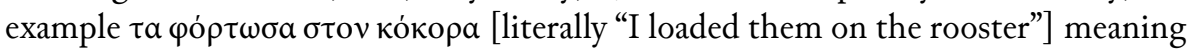
"I did not act at all, as I was feeling lazy".

Therefore, using the aforementioned test as a starting point, a spectrum of fixedness was created. This spectrum includes two types of phrases: the "typical phrases" and the "non-typical phrases". Non-typical phrases include "quasi-phrases" and "conventionalized phrases". In order to be characterized as typical, a phrase

2. The idiom $\delta \varepsilon v \pi \varepsilon \dot{\varphi} \varphi \varepsilon \iota \beta \varepsilon \lambda$ óva [literally “it doesn't drop a needle"] can also be encountered but the two

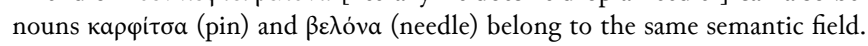


has to meet the exclusive co-occurrence criterion -i.e., the verb constituent of the phrase cannot maintain its meaning if it co-occurs with a noun constituent outside the semantic field to which the noun of the recurrent phrase belongs. In typical phrases, the semantic-lexical articulation between the constituents is so strong that semantic autonomy is restricted or even completely neutralized. A non-typical phrase is one that meets the non-exclusive co-occurrence criterion. In quasi-phrases, the verb retains a) its literal meaning, or b) the meaning it has at the tangible/concrete level, or alternatively c) is used with a non-literal meaning. For example, in the phrase $\tau$ him"] meaning "I was scared stiff by him or his actions" the verb retains its literal

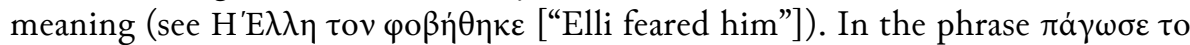
aifa inc [literally "her blood froze"] meaning "she was shocked" the verb has a

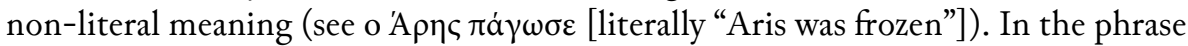

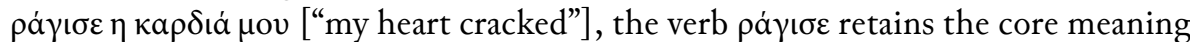
of "cracking without being cut into pieces" that it has in the sentence $\rho \dot{\alpha} \gamma ı \varepsilon$ to $\pi о \tau \eta \dot{\rho ı ~[" t h e ~ g l a s s ~ c r a c k e d "] ~ b y ~ a ~ s e m a n t i c ~ e x t e n s i o n ~ t o ~ a ~ n o n-t a n g i b l e / a b s t r a c t ~}$

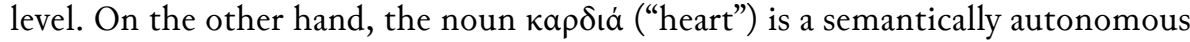
constituent of the phrase since it refers to the inner emotional world. The core meaning of the verb is transposed to an abstract level - at this specific phase we talk about metaphor - while at the same time, the meaning of the whole phrase acquires a new semantic load. This transposition from a tangible to an abstract level bears the connotation of an emotional breakdown.

Conventionalized phrases are those whose verb maintains its fundamental meaning whereas the noun has a parallel to the basic-literal meaning which is a conventionalized meaning ${ }^{3}$. A conventionalized meaning is a meaning widely accepted by a linguistic community and used with all possible connotations acquired

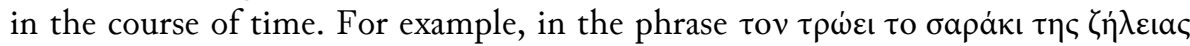
[literally "the woodworm of jealousy eats him"] meaning "jealousy wears him out", the verb eat retains the core meaning of wear. What differentiates this phrase from

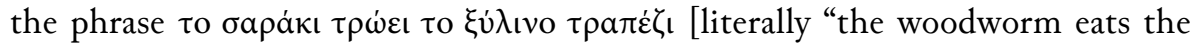

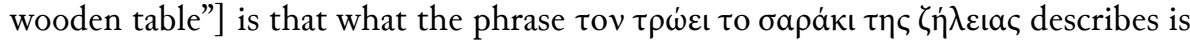
realized on an abstract level, whereas its consequences are perceived on a tangible level. In other words, one can probably recognize somebody who is jealous, but one can hardly see him "eaten alive" by jealousy. In fact, the meaning of the word бapákı is so conventionalized that someone who encounters this word is more likely to recall the meaning of a strong feeling that gradually wears somebody out, than that of the woodworm. Even if both quasi-phrases and conventionalized phrases are characterized by the semantic autonomy of their constituents, an important difference should be noted. In quasi-phrases, the noun constituents are parts of the

3. A constituent's conventionalized meaning should be differentiated from the term "conventionalized expression", which corresponds to the traditional definition of an idiom in the sense that one cannot guess its meaning from the separate meanings of its parts (Nunberg, Sag \& Wasow, 1994). 
body, and therefore they refer to human behavior through a metonymic relationship part/organ - whole/carrier. In conventionalized phrases, the noun constituents are concrete nouns the meaning of which, nevertheless, is captured on an abstract level. Unlike quasi-phrases, conventionalized phrases have a literal counterpart, whereas noun constituents of the conventionalized phrases are held in great semantic autonomy just because of the conventionalized meaning they carry.

In conclusion, typical phrases, quasi-phrases and conventionalized phrases are three discrete categories of idioms that form the spectrum of fixedness. However, a crucial question for those interested in psycholinguistics is to what extent this graded-fixedness model has a psychological reality or, on the contrary, to what extent it is a model with a merely theoretical, lexicographical application.

\subsection{Psycholinguistic study: the psycholinguistic relevance of the model}

Accordingly, the main goal of the experiment presented below is to explore children's sensitivity to these - sometimes subtle - semantic parameters, by testing the effect of the phrase category on access to the idiomatic meaning. This research aims at evaluating the psychological validity of the graded fixedness model we propose based on the notion of semantic autonomy.

Semantic autonomy is the only factor we consider in this experiment. We therefore tried to eliminate two of the factors most likely to interfere, namely familiarity and context. Idioms differ widely in their frequency of occurrence in language. There is also strong empirical evidence in support of the view that familiarity with idioms has a role to play in idiom comprehension, and especially so for younger children (Ortony, Turner \& Larson-Shapiro, 1985; Popiel \& McRae, 1988; Schweigert, 1986; Titone \& Connine, 1994). More particularly, Titone and Connine found an intricate relationship between familiarity and semantic analyzability. Thus, when highly familiar idiomatic sequences are being processed, idiomatic meanings are directly retrieved from the mental lexicon and integrated into the on-going discourse representation (see also Giora, 1997), irrespective of whether the component words bear any relation to the figurative meaning. In contrast, when less familiar idiomatic sequences are being processed, direct retrieval of the idiomatic meanings is more difficult, and, consequently, comprehension is dependent on on-going compositional analysis. In order to establish the non-familiarity of the linguistic material for the participants, additional preliminary research was carried out which will be presented below (see "Materials: construction and evaluation").

As far as context is concerned, there is growing evidence in support of its crucial effect on idiom comprehension. An early sensitivity to context in language learning and comprehension is well documented. Thus, it is not surprising to find that children aged 7 and above understand idiomatic expressions better when these expressions are embedded in a supportive context (Gibbs, 1987, 1991; Levorato \& 
Cacciari, 1992, 1999; Nippold \& Martin, 1989; Cain, Towse \& Knight, 2009). In order to avoid probable interaction of the context with the factor manipulated in the present study, namely semantic autonomy, it was decided to present phrases with no context.

According to the working hypothesis tested by the present study, the greater the semantic autonomy of the phrase's constituents, the better the comprehension is. In particular, we expected that typical phrases whose constituents have restricted semantic autonomy would be more difficult for children to understand than nontypical phrases.

Concerning non-typical phrases, we expected that quasi-phrases would be more difficult for children to understand than conventionalized ones. Conventionalized phrases were expected to be more accessible than quasi-phrases, as their nominal constituents, even if their meaning is perceived on an abstract level, have literal counterparts that seem to be more imageable for young children (see Cacciari \& Levorato, 1998). In theory, the parts of the body that the nominal constituents of the quasi-phrases refer to are also tangible but, in these specific phrases, they do not retain their literal meaning. Seeing that these nouns are substituted with another one they are closely associated with, children need to analyse them metonymically in order to access the meaning of the phrase. This process, naturally, heightens the cognitive load of the idiom processing.

\subsubsection{Preliminary research}

In order to assess idiom comprehension without the confounding factor of prior knowledge, the familiarity of 33 phrases was tested (see Appendix A). In fact, it is hard to know how many children were already familiar with a given expression. Thus, bearing in mind that familiarity with any expression cannot be ruled out a priori, the main idea was to control it assuming that there is an age-dependency in the understanding of any phrase. It is only reasonable to assume that if phrases were found to be unfamiliar for the older students, these would be even more so for the younger ones. Therefore, we chose for the purpose of the present study to conduct this additional preliminary test using fifth graders, who are older than our main student-sample of second graders and fourth graders. 22 fifth graders attending elementary schools in Athens participated in this preliminary research. In the first phase of this familiarity test, the children were asked to complete a questionnaire where they were questioned about each phrase of the material, whether they had heard it before (henceforth called "frequency test"). In the second phase of the preliminary research, the children were presented with a booklet containing the same 33 phrases (see Appendix A). A multiple-choice test was given to them (henceforth "comprehension test"). For each one of them, they had to choose, from three interpretations (idiomatic interpretation, literal interpetation, other interpretation) the one they judged the most appropriate. The interpretations we have called "other" are plausible response options but not connected to the phrases either lexically or conceptually. Statistical analysis showed that, except for the case 
of 4 particular phrases, there was no significant correlation between the two tests. Thus, the material selected for the main research consisted of the phrases that obtained the lowest scores in the comprehension test.

\subsubsection{Main research}

3.3.2.1. Method

- Participants

A total of 200 Greek elementary school children, all native speakers, participated in the experiment. Half of them were second graders (aged from 7 years and I month to 7 years and II months, mean age 7 years and 6 months -56 boys and 44 girls). The other half were fourth graders (aged from 9 years to io years, mean age 9 years and 5 months $-4 \mathrm{I}$ boys and 59 girls). All the children attended elementary schools in Athens. They were all from middle-class families and were in age-appropriate classes. None of the children were dyslexic, nor had cognitive impairments or severe learning difficulties.

- Materials: construction and evaluation

A total of 24 phrases (8 typical, 8 quasi and 8 conventionalized phrases) were selected (see Appendix B). The phrases were presented out of context, in the same order for each participant, distributed so that the same type of phrase (typical, quasi, conventionalized) did not appear consecutively (see Appendix C). Some examples of the three phrase categories are presented below, followed by English word-by-word, literal and idiomatic-meaning translations.

- Example of a typical phrase:

[I] $\Delta \varepsilon v \quad \pi \dot{\varepsilon} \varphi \tau \varepsilon \mathrm{l} \quad \kappa \alpha \rho \varphi i \tau \sigma \alpha$

doesn't drop pin

It doesn't drop a pin.

'It is too crowded.'

- Example of a quasi-phrase:

[2] Tov

him feared (the) eye mine

My eye feared him.

'I was scared stiff by him or his actions.'

- Example of a conventionalized phrase:

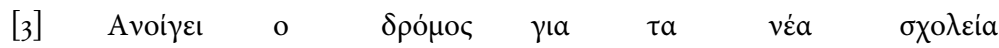

is open the road for the new schools

The road is open for the new schools.

'There are no obstacles left for the construction of the new schools.' 


\section{- Procedure}

Children's understanding of idioms was assessed using a multiple-choice task. Children were tested individually. The test was conducted in a quiet room away from the classroom. The children's task was to read each of the 24 phrases carefully and for each one to choose - in exactly the same way as in the preliminary test - the one they thought right out of three interpretations proposed (idiomatic interpretation, literal interpretation, other interpretation ${ }^{4}$. The instructions for the task were printed on the front cover of the test booklet and read out to the child: "in this booklet there are a number of short expressions, for example $\pi \lambda \eta \rho \omega v \omega \tau \alpha \mu \alpha \lambda \lambda_{\iota} \dot{\alpha}$ $\tau \eta \varsigma \kappa \varepsilon \varphi \alpha \lambda$ nं $\mu$ ov ('to pay an arm and leg'). After each expression, there are three possible meanings. Your job is to choose the right one". Three examples with three multiple-choice options each were given to the children in order to familiarize them with the task. Each of the examples was completed by each child in his/her booklet with the help of the experimenter. Three examples (one for each phrase category) are provided in Appendix D. The experiment took place during the second semester of the school year to ensure that the second graders would already have gained enough experience with reading. The duration of the procedure varied according to the time needed by each participant, but it mainly lasted from 20 to 30 minutes.

- Data coding

The responses were classified into two categories: "Correct" and "Wrong" responses. A response was categorized as a "Correct" one when the participant provided the correct idiomatic meaning of the given idiom. All other responses different from the idiomatic meaning i.e., the literal and other meaning were categorized as wrong responses. For example, if the participant chose for the phrase

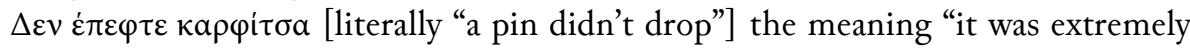
crowded", then it was a "Correct" response but if they chose the meaning "it was extremely noisy" or the meaning "if I drop a pin, nobody would hear it" — which is the literal meaning of the phrase - their response was classified as a "Wrong" one.

\subsubsection{Results}

\section{- Analysis of children's response options}

The mean percentages of correct and wrong responses chosen by children from the two age groups are presented in Table I. According to the $\chi^{2}$ test, there was a significant dependence between age group and type of responses $\left(\chi^{2}=51.573, p=0.000\right.$, $\mathrm{df}=\mathrm{I})$ : the younger the children were, the greater the number of wrong responses (literal and other) was. In particular, percentages of correct responses were lower than percentages of wrong responses for younger children (32.6\% vs. $67.4 \%)$. The

4. In the multiple-choice task, an effort was made to simplify, as far as possible, the idiomatic interpretation of the phrases proposed to the children. For this reason, in some cases it can be observed that the idiomatic interpretation proposed (see Appendix B) is not the same as the idiomatic meaning of the phrase as given in the dictionaries (see Appendix A). 
reverse pattern was observed for older children $(56.2 \%$ vs. $43.8 \%$ for the correct and wrong responses, respectively) (see Table I). It can be observed, however, that overall children's performance is quite poor.

\begin{tabular}{|l|l|l|}
\hline Age group & \multicolumn{2}{|c|}{ Type of responses } \\
\hline & Correct & Wrong \\
\hline Second graders & 33 & 67 \\
\hline Fourth graders & 56 & 44 \\
\hline
\end{tabular}

Table 1. Percentages of correct and wrong responses for both age groups

As regards the second graders, detailed data analysis demonstrated that the percentages of wrong responses (literal and other) were, for 20 out of the 24 phrases, significantly higher than the percentages for the correct (idiomatic) responses. In two phrases, no significant difference was found whereas in only two phrases (Io and I3) (see Appendix C) the percentages of correct responses were higher than the percentages of wrong responses. Possible explanations of the reasons why these two phrases were accessed successfully could be that the first one is a conventionalized phrase which, in addition, refers to a rather well-known subject for many children i.e., football, whereas the second one is a phrase whose verb retains its literal meaning.

These results suggest that, in general, children of this age level find it difficult to understand the meaning of the phrases belonging to the spectrum of fixedness.

As far as fourth graders' performance is concerned, the percentages of correct responses were significantly higher than the percentages of wrong responses for 9 out of 24 phrases (I, 2, 4, 9, IO, II, I2, I3, 19) (see Appendix C). For 3 phrases, the percentages of wrong responses were higher than the percentages of correct responses $(3,8,18)$ whereas for the remaining I2 phrases, no significant difference was found (see Appendix C). These results suggest that older children are better at understanding the meaning of the phrases proposed. One interesting finding worth pointing out is that $80 \%$ of the children's choices at both age levels are either idiomatic or literal. Children's choices which have been collectively grouped as "other" (corresponding to plausible responses but not connected to the phrases either lexically or conceptually) account for a marginal proportion. In other words, interpretations that seem to bear no obvious relationship to the lexical data of the phrase are less acceptable by children. Taken together, these results suggest that children try to get access to the meaning of the phrase either literally or non-literally.

\section{- The effect of phrase category on the type of response options}

More interesting for the aim of the present study was the significant effect of the phrase category on the type of responses given by second and fourth graders. 
A $2 \times 3$ (i.e., age $x$ phrase category) analysis of Variance (ANOVA) was applied. The results showed that, for both age groups, the percentages of idiomatic responses i.e., correct responses differed significantly depending on the phrase category: for the second graders $(\mathrm{F}=\mathrm{I} 0.403, \mathrm{p}=0.000)$ and for the fourth graders $(\mathrm{F}=\mathrm{II} .6 \mathrm{I} 2$, $\mathrm{p}=0.000$ ). Similarly, the results showed that, for both age groups, the percentages of literal responses i.e., wrong responses, differed significantly depending on the phrase category: for the second graders $(\mathrm{F}=\mathrm{I} 2.928, \mathrm{p}=0.000)$ and for the fourth graders $(\mathrm{F}=\mathrm{I3} .958, \mathrm{p}=0.000)$.

\begin{tabular}{|c|c|c|c|c|}
\hline \multirow{3}{*}{ Age group } & \multirow{3}{*}{ Phrase category } & \multicolumn{3}{|c|}{ Type of responses } \\
\hline & & \multirow{2}{*}{$\frac{\text { Correct }}{\text { Idiomatic }}$} & \multicolumn{2}{|c|}{ Wrong } \\
\hline & & & Literal & Other \\
\hline \multirow[t]{3}{*}{ Second graders } & Typical & 26 & 56 & I8 \\
\hline & Quasi & 34 & 45 & $2 \mathrm{I}$ \\
\hline & Conventionalized & 38 & $4 \mathrm{I}$ & $2 \mathrm{I}$ \\
\hline \multirow[t]{3}{*}{ Fourth graders } & Typical & 50 & 29 & $2 \mathrm{I}$ \\
\hline & Quasi & 54 & 28 & I8 \\
\hline & Conventionalized & 65 & 15 & 20 \\
\hline
\end{tabular}

Table 2. Percentages of idiomatic (correct), literal (wrong) and other (wrong) response options by age group and phrase category

More specifically, for the second graders, significant differences were observed concerning idiomatic responses i.e., correct responses, when comparing between I) typical phrases and quasi-phrases (26\% vs. $34 \%)$ and 2 ) typical phrases and conventionalized phrases ( $26 \%$ vs. $38 \%$ ), whereas between quasi-phrases and conventionalized phrases no significant difference was found. Significant differences were also observed concerning literal responses i.e., wrong responses, when comparing between I) typical phrases and quasi-phrases ( $56 \%$ vs. $45 \%$ ) and 2) typical phrases and conventionalized phrases $(56 \%$ vs. $41 \%)$ whereas between quasi-phrases and conventionalized phrases no significant difference was found (see Table 2). These results indicate that children, although their performance is overall very poor, find it more difficult to understand the meaning of the phrases when their components do not have semantic autonomy.

For the fourth graders, significant differences were observed concerning idiomatic responses when comparing between I) typical phrases and conventionalized phrases $(50 \%$ vs. $65 \%)$ and 2 ) quasi-phrases and conventionalized phrases ( $54 \%$ vs. $65 \%)$ whereas between typical phrases and quasi-phrases no significant difference was found (see Table 2). Significant differences were also observed concerning literal responses when comparing between I) typical phrases and conventionalized phrases $(29 \%$ vs. $15 \%)$ and 2 ) quasi-phrases and conventionalized phrases (28\% vs. $15 \%)$ 
whereas between typical phrases and quasi-phrases no significant difference was found (see Table 2). These results show that, except for conventionalized phrases, which are quite well understood (65\% of correct responses), the comprehension of typical and quasi-phrases barely reached half of the correct responses $(50 \%$ and $54 \%$, respectively). These results suggest that in order for the children to be able to take advantage of the semantic autonomy of the constituents of an idiom, this autonomy has to be of a high level. This is the case of conventionalized phrases but it is not that of the quasi-phrases, which still remain quite opaque for young children. As far as typical phrases are concerned, the higher degree of familiarity that fourth graders may have with these phrases could account for their better understanding. Indeed, even if an effort was made to control children's familiarity with the phrases presented, it cannot be excluded with certainty that, in the course of time, some of them appear in children's linguistic input more frequently than in the past.

Overall, despite the developmental change observed herein, a common pattern in second graders' and fourth graders' performance emerged, namely the significant difference between typical and conventionalized phrases. In other words, it seems that, even at the age of 7.6 , children are sensitive to the semantic differences between the most opaque and the most transparent phrases. It seems that children need to have better developed skills, so as to understand phrases whose meaning is related indirectly, i.e., through a metaphor, to the figurative meaning of the phrase. This is the case of quasi-phrases.

\section{Discussion}

Two objectives were set at the beginning of the present study. The first objective was to contribute to the investigation of the most crucial question in the idiom literature, which is the question of fixedness. For this purpose, a semantic-lexical categorization of 470 Greek phrases was attempted, those having a fixed relation between verb and subject. We first organized them syntactically according to "lexicongrammar" principles (M. Gross, 1975). The present analysis supplied us with the argument that any syntactic differences between phrases and free expressions are of limited significance. By subsequent application of lexical and semantic criteria, it was shown that the constituents of the phrases are more or less characterized by semantic autonomy. This led us to form a three-category model of semantic fixedness.

Initially, two major categories were distinguished, based on the strength of the semantic-lexical articulation between verb and subject: typical phrases and non-typical phrases. Typical phrases were considered to be the phrases that meet the exclusive co-occurrence criterion: the verb does not co-occur with another noun constituent, while at the same time maintaining the meaning it bears in the idiomatic phrase

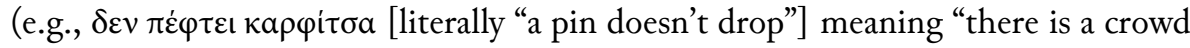
of people"). Conversely, non-typical phrases are those whose constituents have a certain semantic autonomy. Non-typical phrases were further categorized into: 
a) quasi-phrases and b) conventionalized phrases. Quasi-phrases are those where the verb maintains either its literal or non-literal meaning (e.g., тоv

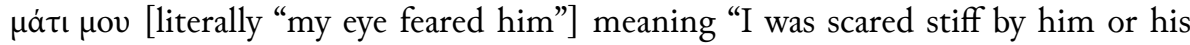
actions") or alternatively maintaining its core meaning at a tangible/concrete level (e.g.,

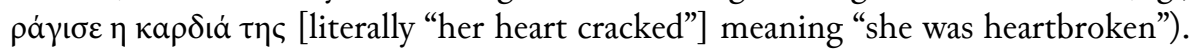
Conventionalized phrases are those where the verb maintains its fundamental meaning whereas the noun has a second meaning parallel to the basic one, a conventionalized

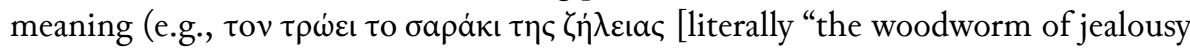
eats him"] meaning "jealousy wears him out").

The second objective of the present study was to assess the psychological reality of the graded fixedness model proposed. To this end, we investigated the extent to which Greek elementary school children aged between 7.6 and 9.5 are sensitive to the aforementioned - in some cases subtle - semantic distinctions of idiomatic phrases of their language, as identified by linguistic analysis. Based on previous research we expected that, in general, older children would perform better than younger ones and that phrases whose constituents have semantic autonomy would be better understood than phrases with no semantic autonomy.

The findings in relation to our hypotheses can be summarised as follows: first, older children demonstrated much higher levels of comprehension for all three types of phrase. A literal processing tendency of the younger children was apparent. It is precisely this tendency that forms the underlying reason why younger children (7.6-year-olds) appeared to have serious difficulties in understanding the idiomatic meaning of the phrases belonging to the spectrum of fixedness. Second, both groups were more likely to select the idiomatic interpretation when presented with non-typical phrases. However, younger children's performance is overall so poor that nobody can argue with certainty that children of this age are capable of taking advantage - even to a lesser degree than the older children - of the constituents' semantic autonomy. Suffice to say that they display a certain level of sensitivity to the semantic differentiations of the linguistic material used in this experiment. This sensitivity seems to develop considerably until the age of 9.5, since the children of this age achieve a quite high level of comprehension when processing the more transparent of the non-typical phrases i.e., the conventionalized ones. In fact, there is no doubt that children are able to work out the meaning of the phrase taking advantage of the meaning of its individual parts, but this meaning has to be close enough to the idiomatic meaning of the phrase for children to be able to grasp it. On the contrary, if it is not clear to the children how the meaning of the individual constituents is related to the idiomatic meaning of the phrase, then idiom comprehension becomes difficult or even impossible. For most children at the age of 7.6, the comprehension of quasi-phrases proved to be impossible. Even at the age of 9.5, almost half of the responses were literal. That suggests that more efficient and more sophisticated strategies are needed so that the non-literal relation, which the constituents of these phrases bear with the figurative meaning, can be recognized as such and processed adequately. 


\section{References}

Ackerman, B.P. 1982. On Comprehending Idioms: Do Children Get the Picture? Journal of Experimental Child Psychology 33 (3): 439-454.

Babiniotis, G. (dir.) 2002. Dictionary of Modern Greek. Athens: Lexicology Center [ $2^{\text {nd }}$ edition]. 
Bobrow, S.A. \& Bell. S.M. 1973. On Catching on to Idiomatic Expressions. Memory and Cognition I (3): 343-346.

Cacciari, C. \& Levorato, M.C. 1998. The Effect of Semantic Analyzability of Idioms in Metalinguistic Tasks. Metaphor and Symbol I3 (3): 159-I77.

Caillies, S. \& Le Sourn-Bissaoui, S. 2006. Idiom Comprehension in French Children: A Cock-and-Bull Story. European Journal of Developmental Psychology 3 (2): 189-206.

Cain, K., Towse, A.S. \& Knight, R.S. 2009. The Development of Idiom Comprehension: An Investigation of Semantic and Contextual Processing Skills. Journal of Experimental Child Psychology IO2 (3): 280-298.

Сномsкy, N. 1980. Rules and Representations. New York: Columbia University Press.

FотоPOULOU, A. 1993. Une classification des phrases à compléments figés en grec moderne-étude morphosyntaxique des phrases figées. $\mathrm{PhD}$ thesis. Université Paris VIII.

Fraser, B. 1970. Idioms within a Tranformational Grammar. Foundations of language 6 (I): $22-42$.

GibBs, R.W. 1987. Linguistic Factors in Children's Understanding of Idioms. Journal of Child Language I4: $569-586$.

Gibbs, R.W. 199I. Semantic Analyzability in Children's Understanding of Idioms. Journal of Speech and Hearing Research 34 (3): 613-620.

GibBs, R.W. et al. 1997. Metaphor in Idiom Comprehension. Journal of Memory and Language 37 (2): I4I-I54.

Gibbs, R.W. \& Nayak, N.P. 1989. Psycholinguistic Studies on the Syntactic Behavior of Idioms. Cognitive Psychology 2I (I): IOO-I38.

Gibbs, R.W., Nayak, N.P. \& Cutting, C. 1989. How to Kick the Bucket and not Decompose: Analyzability and Idiom Processing. Journal of Memory and Language 28 (5): 576-593.

GiorA, R. 1997. Understanding Figurative and Literal Language: The Graded Salience Hypothesis. Cognitive Linguistics 8 (3): 183-206.

Glucksberg, S. I993. Idiom Meaning and Allusional Content. In C. Cacciari \& P. TABossi (eds), Idioms: Processing, Structure, and Interpretation. Hillsdale (N.J.): Lawrence Erlbaum: 3-26.

Gross, G. 1994. Classes d'objet et description des verbes. Langages 28 (II5): 15-30.

Gross, M. 1975. Méthodes en syntaxe. Paris: Hermann.

Gross, M. 1982. Une classification des phrases “figées” du français. Revue québécoise de linguistique II (2): $15 \mathrm{I}-\mathrm{I} 85$.

Gross, M. 1988. Les limites de la phrase figée. Langages 23 (90): 7-22.

Hamblin, J. \& Gibbs, R.W. I999. Why You Can't Kick the Bucket as You Slowly Die: Verbs in Idiom Comprehension. Journal of Psycholinguistic Research 28 (I): 25-39.

ILSP. Hellenic National Corpus: http://hnc.ilsp.gr/.

Lamiroy, B. 2003. Les notions linguistiques de figement et de contrainte. Linguisticae Investigationes $26(\mathrm{I}): 53-66$.

Levorato, M.C. \& Cacciari, C. 1992. Children's Comprehension and Production of Idioms: The Role of Context and Familiarity. Journal of Child Language 19 (2): 415-433. 
Levorato, M.C. \& Cacciari, C. 1999. Idiom Comprehension in Children: Are the Effects of Semantic Analyzability and Context Separable? European Journal of Cognitive Psychology II (I): 5I-66.

Lorentzen, H. 1996. Lemmatization of Multi-Word Lexical Units: In which Entry? In M. Gellerstam et al. (eds), Euralex'96 Proceedings. Göteborg: Göteborg University, Department of Swedish: 415-42I.

Manolis Triantafyllidis Foundation 1998. Dictionary of Modern Greek. Thessaloniki: Institute for Greek Studies.

Mini, M. 2009. Linguistic and Psycholinguistic Study of Fixed Verbal Expressions with Fixed Subject in Modern Greek: A Morphosyntactic Analysis, Lexicosemantic Gradation and Processing by Elementary School Children. Unpublished doctoral dissertation. University of Patras.

Nippold, M.A. 1998. Later Language Development: The School-Age and Adolescent Years. Austin (Tex.): Pro-Ed.

Nippold, M.A. \& Duthie, J.K. 2003. Mental Imagery and Idiom Comprehension: A Comparison of School-Age Children and Adults. Journal of Speech, Language, and Hearing Research 46 (4): 788-799.

NipPOLD, M.A. \& MARTin, S.T. I989. Idiom Interpretation in Isolation versus Context: A Developmental Study with Adolescents. Journal of Speech and Hearing Research 32 (I): 59-66.

Nippold, M.A. \& Rudzinski, M. 1993. Familiarity and Transparency in Idiom Explanation: A Developmental Study of Children and Adolescents. Journal of Speech and Hearing Research 36 (4): 728-737.

Nippold, M.A. \& TAYLOR, C.L. 1995. Idiom Understanding in Youth. Further Examination of Familiarity and Transparency. Journal of Speech and Hearing Research 38 (2): 426-433.

NipPOLD, M.A. \& TAYLOR, C.L. 2002. Judgments of Idiom Familiarity and Transparency: A Comparison of Children and Adolescents. Journal of Speech, Language, and Hearing Research 45 (2): 384-39I.

Nunberg, G. 1979. The Non-Uniqueness of Semantic Solutions: Polysemy. Linguistics and Philosophy 3 (2): I43-I84.

Nunberg, G., SaG, I. \& Wasow, T. 1994. Idioms. Language 70 (3): 491-538.

Ortony, A. et al. 1978. Interpreting Metaphors and Idioms: Some Effects of Context on Comprehension. Journal of Verbal Learning and Verbal Behavior I7 (4): 465-477.

Ortony, T., Turner, T.J. \& LARson-Shapiro, N. 1985. Cultural and Instructional Influences on Figurative Language Comprehension by Inner City Children. Research in the Teaching of English I9 (I): 25-36.

Popiel, S.J. \& McRae, K. 1988. The Figurative and Literal Senses of Idioms, or all Idioms are not Used Equally. Journal of Psycholinguistic Research I7 (6): 475-487.

Schweigert, W. 1986. The Comprehension of Familiar and less Familiar Idioms. Journal of Psycholinguistic Research I5 (I): 33-45.

Swinney, D. \& Cutler, A. 1979. The Access and Processing of Idiomatic Expressions. Journal of Verbal Learning and Verbal Bebavior i8 (5): 523-534. 
Tabossi, P., Fanari, R. \& Wolf, K. 2008. Processing Idiomatic Expressions: Effects of Semantic Compositionality. Journal of Experimental Psychology: Learning, Memory, and Cognition 34 (2): 313-327.

Titone, D.A. \& Connine, C.M. 1994. Comprehension of Idiomatic Expressions: Effects of Predictability and Literality. Journal of Experimental Psychology: Learning, Memory and Cognition 20 (5): II26-II38.

Titone, D.A. \& Connine, C.M. 1999. On the Compositional and Noncompositional Nature of Idiomatic Expressions. Journal of Pragmatics 3I (I2): I655-I674.

VAn Der Linden, E.J. 1992. Incremental Processing and the Hierarchical Lexicon. Computational Linguistics I8 (2): 219-238.

\section{APPENDIX A. The 33 Greek phrases (with literal and idiomatic translations in English) which were used in the preliminary research}

\section{Typical phrases}

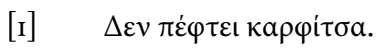

A pin doesn't drop.

'It is extremely crowded.' / 'There is a tight squeeze.'

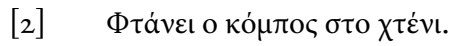

The knot came to the comb.

'This cannot go on.' / 'Things came to a head.'

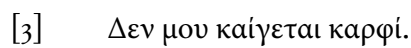

I don't burn a nail.

'I don't give a damn.' / 'I couldn't care less.'

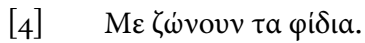

I am surrounded by snakes.

'I am extremely worried about something.' / 'I am alarmed.'

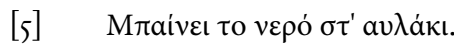

The water goes into the ditch.

'Things have taken their course.' / 'The process started to function in an orderly way.'

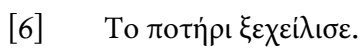

The glass overflowed.

'This was the last straw.' / 'My patience has been exhausted.'

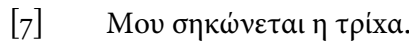

My hairs are put up.

'My hair stands on end.' / 'I was disgusted, terrified, horrified, extremely displeased.' 


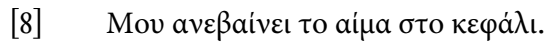

The blood rises up to my head.

'My blood is up.' / 'I lose my temper.'

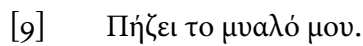

My mind thickens.

'I become mature.'

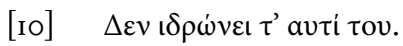

His ear doesn't sweat.

'It cuts no ice with him.' / 'He doesn't turn a hair.' / 'He doesn't give a damn.' / 'He couldn't care less.'

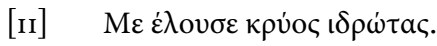

A cold water gave me a bath.

'I am scared stiff.' / 'I have been in a cold sweat.'

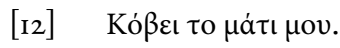

My eye cuts.

'I can easily recognize the quality of something.'

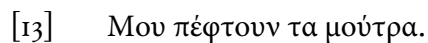

My face falls down.

'I lose face.' / 'I am too ashamed.'

\section{Quasi-phrases}

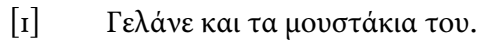

Even his moustache laughs.

'He is cock-a-hoop.' / 'He is over the moon about something.' / 'He is laughing all the way to the bank.' / 'He is delighted.'

[2] Tov

My eye was afraid of him.

'I was scared of him or of his actions or of what he might do.'

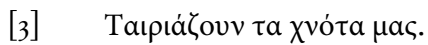

Our breath matches.

'We have a lot in common.' / 'We take to each other.' / 'We think and act in a similar way.'

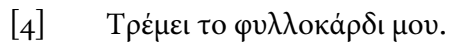

My heart shakes.

'I am all in a tremble.' / 'I quake in my shoes.' / 'I am paralysed by fear.' 


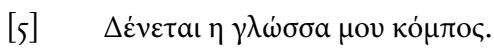

My tongue is tied.

'I am tongue-tied.' / 'I am speechless.' / 'I am lost for words.'

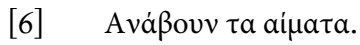

The blood catches fire.

'An explosive situation is reached that might result in a fight.'

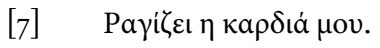

My heart breaks.

'I am heartbroken.' / 'I am in deep grief.'

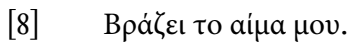

My blood boils.

'I am hot-tempered.' / 'My blood is up.' / 'I am full of energy.'

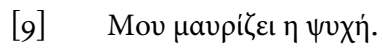

It blackens my soul.

'It gets me down.' / 'I am in deep sorrow.'

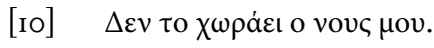

It doesn't get into my mind. / My mind doesn't hold it.

'It is beyond my comprehension.' / 'It is incredible.'

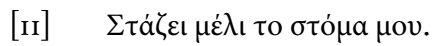

My mouth is dripping honey.

'I say honeyed words.'

\section{Conventionalized phrases}

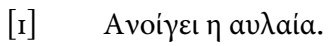

The curtain opens.

'The curtain rises.' / 'Something commences.'

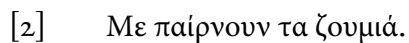

I am taken by juice. / I am swept off by juice.

'I am brought to tears.'

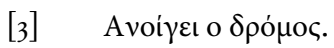

The road is open.

'The road is now open, no obstacle ahead.' / 'To pave the way to something.' /

'There are no obstacles/hindrances left.'

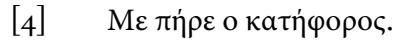

I was swept away by the descent/slope.

'I am going downhill.' / 'I am going to the bad.' 


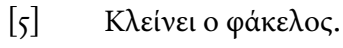

The envelope is closed.

'The case is closed.' / 'I no longer see to a case.'

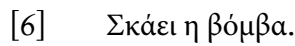

The bomb goes off.

'The bomb goes off.' / 'Something is brought to light causing an uproar.' / 'Something totally unforeseeable has happened or has been revealed.'

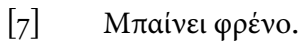

A brake is set.

'Put a brake on something, situation, habit, process etc.' / 'The course of events is delayed or comes to a standstill.'

[8] Aveßaivouv ot тóvol.

The tones are raised.

'The situation reaches a point of high tension.' / 'The discussion is heated up.'

\section{APPENDIX B. The whole set of Greek phrases \\ (with literal and idiomatic translations in English) \\ that participants were presented with}

\section{Typical phrases}

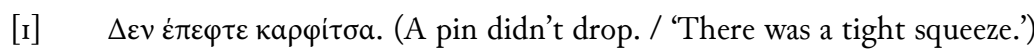

I. It was extremely crowded. (I)

2. It was extremely noisy. (O)

3. If I drop a pin, nobody would hear it. (L)

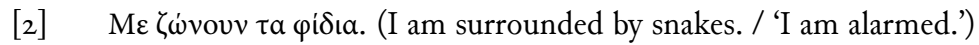

I. I have nightmares with snakes. (L)

2. I start worrying a lot. (I)

3. Time doesn't seem to pass. (O)

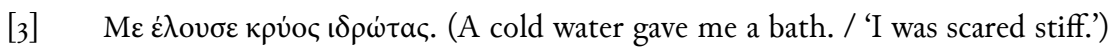

I. I was scared stiff. (I)

2. I was drenched in sweat. (L)

3. I got angry with myself. $(\mathrm{O})$

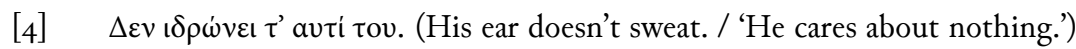

I. He keeps on swindling. (O)

2. He doesn't hear all that well as his ears are clogged. (L)

3. He cares about nothing. (I) 


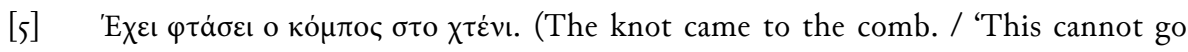
on.')

I. I am upset as my comb has stuck on a knot. (L)

2. You have no patience at all. $(\mathrm{O})$

3. This cannot go on anymore. (I)

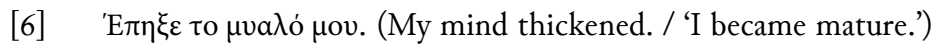

I. My mind got tired. (L)

2. As I matured, I became wiser. (I)

3. I have good relationships with everybody. (O)

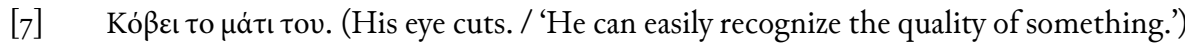

I. He can easily distinguish if something is good or bad. (I)

2. He sees very well and particularly with one eye. (L)

3. He trusts nobody but himself. (O)

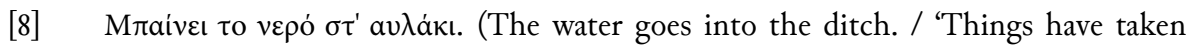
their course.')

I. There is a huge problem. (O)

2. Things are starting to go well. (I)

3. When it rains, the road is not flooded. (L)

\section{Quasi-phrases}

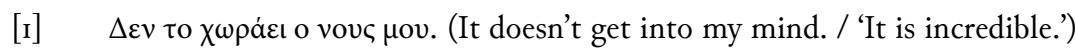

I. My mind doesn't hold it. (L)

2. I do not care for something. (O)

3. I cannot believe it. (I)

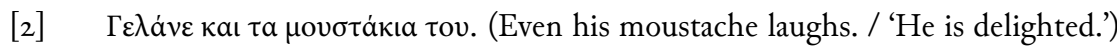

I. He is very satisfied. (I)

2. He is laughing his head off. (L)

3. He believes that he is somebody. $(\mathrm{O})$

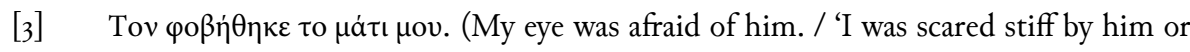
his actions.')

I. I tried to calm him down. (O)

2. I stopped staring at him. (L)

3. I was scared stiff of him. (I)

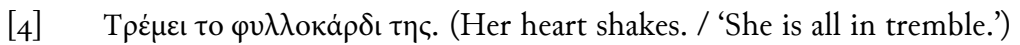

I. She has a heartache. (L)

2. She is concerned and worried. (I)

3. She has bad dreams. (O) 


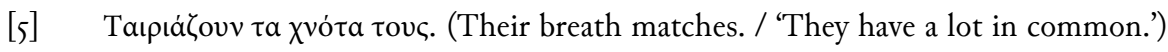

I. They feel each other's breath. (L)

2. They are sitting on the same desk. (O)

3. As they are usually of the same opinion, they never argue. (I)

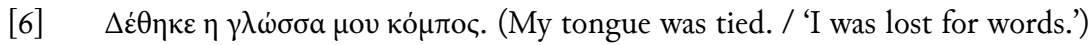

I. I was startled and I was lost for words. (I)

2. I bit my tongue and cut it. ( $\mathrm{L}$ )

3. I told a lie. (O)

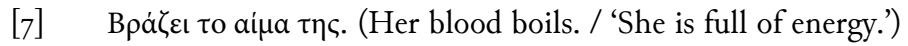

I. She is full of energy. (I)

2. She repeatedly has her blood tested to check her health. (L)

3. She is really anxious. $(\mathrm{O})$

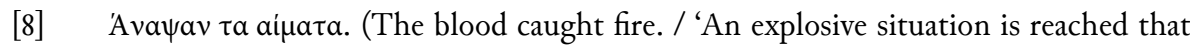
might result in a fight.')

I. A serious fight was just avoided. (I)

2. The heat was unbearable. (L)

3. We were very anxious. $(\mathrm{O})$

\section{Conventionalized phrases}

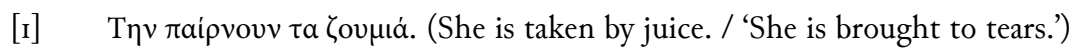

I. She is highly moved and she is brought to tears. (I)

2. She gets a fruit juice to drink. (L)

3. She starts crying. $(\mathrm{O})$

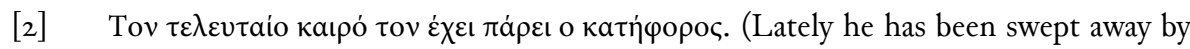
the slope. / 'Lately he is going downhill.')

I. Lately, he has been speeding down the hill. (L)

2. Lately, he has not been doing all that well. (I)

3. Lately, he has been far too anxious. $(\mathrm{O})$

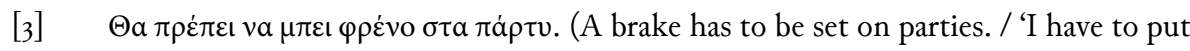
a brake on parties.')

I. I should not be so late in returning home from parties. (O)

2. I should not go too frequently to parties. (I)

3. I should not go to parties anymore before having the brakes on my bicycle repaired. (L)

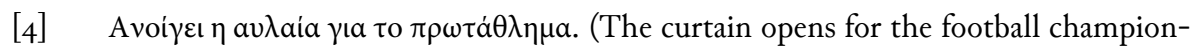
ship. / 'The football championship commences.')

I. The football championship commences. (I)

2. The championship is a great event. $(\mathrm{O})$

3. The stadium is open-air. (L) 


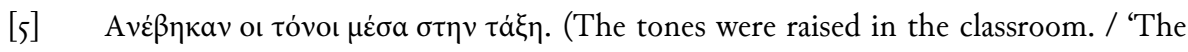
situation in the classroom reached a point of high tension.')

I. The children were left by themselves and they didn't know what to do. (O)

2. The children corrected the stress marks as there were mistakes in them. (L)

3. The children started shouting and came closer to a fight. (I)

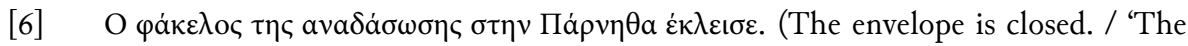
case is closed.')

I. They are not going to deal anymore with the issue of the reforestation at mount Parnitha. (I)

2. They closed and sealed the envelope. (L)

3. The case of the reforestation at mount Parnitha is really weird. $(\mathrm{O})$

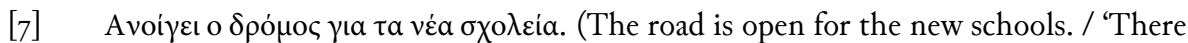
are no obstacles left for the construction of the new schools.')

I. Everybody impatiently awaits for the construction of the new schools. (O)

2. The road was properly cleaned in front of the new schools. (L)

3. There is no obstacle left and the construction of the new schools is now starting. (I)

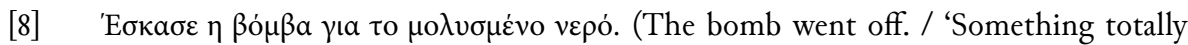
unforeseeable has been revealed.')

I. A loud noise, just like a bomb, was heard. (L)

2. We were suddenly informed that even the water was contaminated. (I)

3. The bit of news we heard did not impress us that much. (O)

\section{APPENDIX C. The whole set of Greek phrases (with literal and idiomatic translations in English) in the order in which participants were presented with}

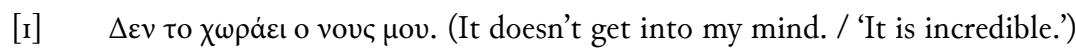
I. My mind doesn't hold it. (L)
2. I do not care for anything. (O)
3. I cannot believe it. (I)

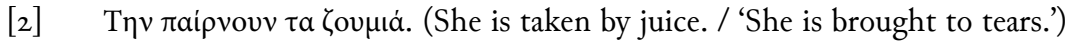

I. She is highly moved and she is brought to tears. (I)

2. She gets a fruit juice to drink it. (L)

3. She starts crying. $(\mathrm{O})$

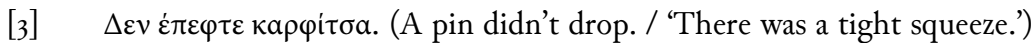

I. It was extremely crowded. (I)

2. It was extremely noisy. (O)

3. If I drop a pin, nobody would hear it. (L) 


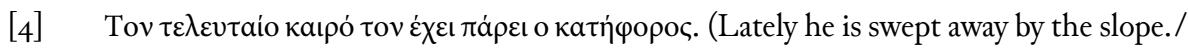
'Lately he is going downhill.')

I. Lately he is speeding down the hill. (L)

2. Lately, he is not doing all that well. (I)

3. Lately, he is far too anxious. (O)

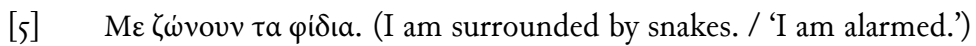

I. I have nightmares with snakes. (L)

2. I start worrying a lot. (I)

3. Time doesn't seem to pass. (O)

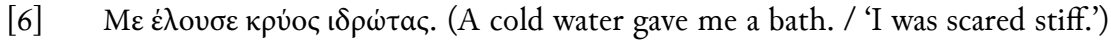

I. I was scared stiff. (I)

2. I was drenched in sweat. (L)

3. I got angry with myself. (O)

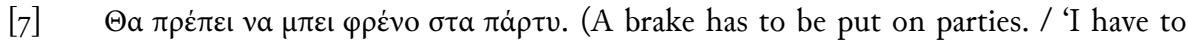
put a brake on parties.')

I. I should not be so late in returning home from parties. (O)

2. I should not go too frequently to parties. (I)

3. I should not go to parties anymore before having the brakes on my bicycle repaired. (L)

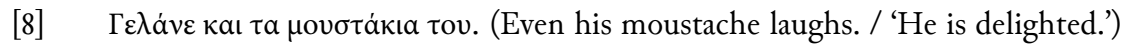

I. He is very satisfied. (I)

2. He is laughing his head off. (L)

3. He believes that he is somebody. (O)

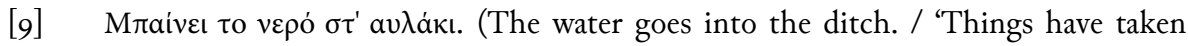
their course.')

I. There is a huge problem. (O)

2. Things are starting to go well. (I)

3. When it rains, the road is not flooded. (L)

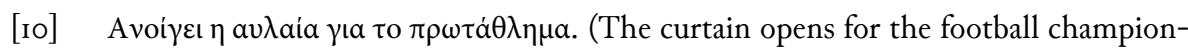
ship. / 'The football championship commences.')

I. The football championship commences. (I)

2. The championship is a great event. $(\mathrm{O})$

3. The stadium is open-air. (L)

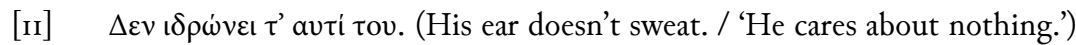

I. He keeps on swindling. (O)

2. He doesn't hear all that well as his ears are clogged. (L)

3. He cares about nothing. (I) 


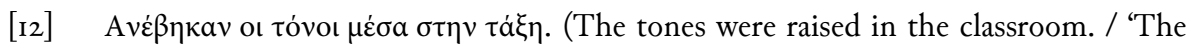
situation in the classroom reached a point of high tension.')

I. The children were left by themselves and they didn't know what to do. (O)

2. The children corrected the stress marks as there were mistakes in them. (L)

3. The children started shouting and came close to fighting. (I)

[ı3] Tov his actions.')

I. I tried to calm him down. (O)

2. I stopped staring at him. (L)

3. I was scared stiff of him. (I)

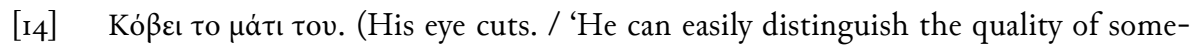
thing.')

I. He can easily distinguish if something is good or bad. (I)

2. He sees very well and particularly with one eye. (L)

3. He trusts nobody but himself. (O)

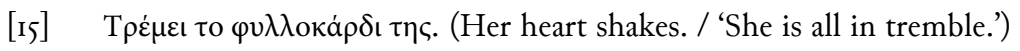

I. She has a heartache. (L)

2. She is concerned and worried. (I)

3. She has bad dreams. $(\mathrm{O})$

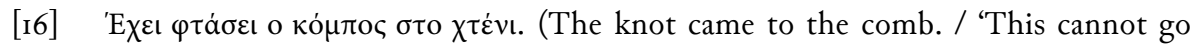
on.')

I. I am upset as my comb has stuck on a knot. (L)

2. You have no patience at all. (O)

3. This cannot go on anymore. (I)

[17] O case is closed.')

I. They are not going to deal with the issue of reforestation at Mount Parnitha anymore. (I)

2. They closed and sealed the envelope. (L)

3. The case of reforestation at Mount Parnitha is really weird. (O)

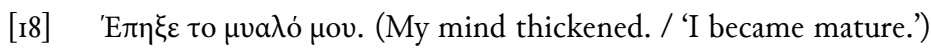

I. My mind got tired. (L)

2. As I matured, I became wiser. (I)

3. I have good relationships with everybody. (O)

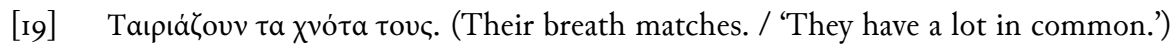

I. They feel each other's breath. (L)

2. They are sitting on the same desk. (O)

3. As they are usually of the same opinion, they never argue. (I) 


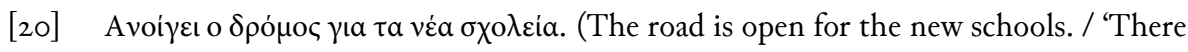
are no obstacles left for the construction of the new schools.')

I. Everybody is waiting impatiently for the construction of the new schools. (O)

2. The road was properly cleaned in front of the new schools. (L)

3. There is no obstacle left and the construction of the new schools is now starting. (I)

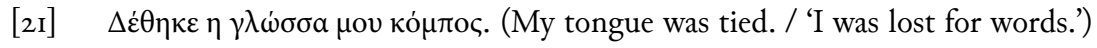

I. I was startled and I was lost for words. (I)

2. I bit my tongue and cut it. (L)

3. I told a lie. (O)

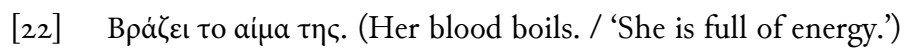

I. She is full of energy. (I)

2. She repeatedly has her blood tested to check her health. (L)

3. She is really anxious. $(\mathrm{O})$

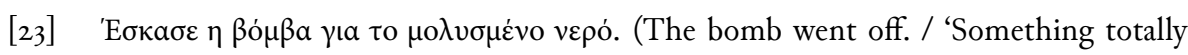
unforeseeable has been revealed')

I. A loud noise, just like a bomb, was heard. (L)

2. We were suddenly informed that even the water was contaminated. (I)

3. The bit of news we heard did not impress us that much. (O)

[24] Ava might result in a fight.')

I. A serious fight was just avoided. (I)

2. The heat was unbearable. (L)

3. We were very anxious. $(\mathrm{O})$

\section{APPENDIX D. Three examples (one for each phrase category) of materials with multiple-choice options}

Typical phrase:

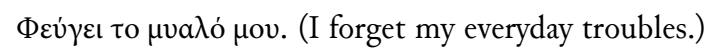

\section{Question and options:}

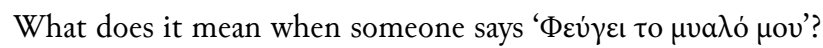

A. My mind goes away. (L)

B. I am indifferent. (O)

C. I forget my everyday troubles. (I)

\section{Quasi-phrase:}

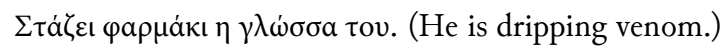




\section{Question and options:}

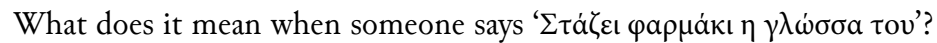

A. His tongue is dripping venom. (L)

B. He tells malicious lies. (I)

C. He talks too much. (O)

\section{Conventionalized phrase:}

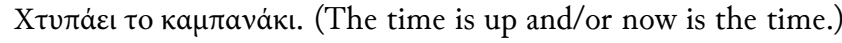

\section{Question and options:}

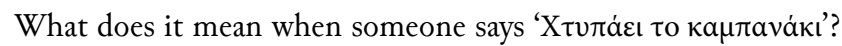
A. The bell rings. (L)
B. The time is up. (I)
C. He is very noisy. (O) 